Logos. Anales del Seminario de Metafísica

ISSN: $1575-6866$

https://dx.doi.org/10.5209/asem.65860

\title{
El caso Sócrates y el Estado hegeliano (Reflexiones a propósito de un libro de Pedro Cerezo Galán)
}

Javier Fabo Lanuza ${ }^{1}$

Cerezo Galán, Pedro: Hegel y el reino del espíritu, Granada, Editorial Universidad de Granada, 2018

Escribir un libro sobre Hegel tras casi dos siglos de hegelianismo no es tarea fácil, sobre todo cuando a ese hegelianismo han contribuido algunas de las figuras más destacadas del último siglo. La audacia de Kojève, la profundidad de Hyppolite, la originalidad de Derrida, etc., hacen muy difícil el poder emprender hoy esta tarea con pertinencia. Al libro de Pedro Cerezo Galán es justo reconocerle esta pertinencia. En primer lugar, porque evita las generalidades excesivamente simplificadoras, tan abundantes en la bibliografía secundaria sobre Hegel, aportando la precisión y el matiz conceptual necesarios para corregir los malentendidos que se sedimentan en ella. En segundo lugar, porque no busca mantenerse en la comodidad de los tópicos mil veces trillados por los comentaristas, sino que se desplaza audazmente hacia los recodos más problemáticos del Sistema hegeliano, para moverse con maestría en las constelaciones conceptuales más comprometidas.

"Enajenación" y "extrañamiento", "ley" y "destino", "vida" y "amor", "perdón" y "reconciliación", "moralidad" y "eticidad", "sociedad" y "comunidad", "política" y "religión", son algunos de los puntos luminosos que articulan estas constelaciones. Su complejo entramado deja entrever la seriedad de un trabajo reposado, que ha ido madurando con el tiempo, sin la prisa que a veces caracteriza al ámbito académico de nuestros días. Hegel y el reino del espíritu es una compilación de trabajos elaborados a lo largo de veinticinco años de ocupación con el pensamiento de Hegel, en los que ha ido cristalizando poco a poco un estilo de lectura muy serio y autoexigente, bien armado técnicamente, y de gran hondura filosófica. El resultado es una línea de interpretación muy sólida y bien medida en el contexto del debate filosófico de la segunda mitad del siglo XX, madurada (y entrañada) en una larga y rica biografía intelectual, en la que también la actividad política e institucional ha tenido un lugar destacado, y que hace buena la convicción hegeliana, orteguiana y heideggeriana de la incardinación de lo sistemático en la historia y en la vida.

Tal convicción se expresa aquí, con contundencia, en la forma de una apuesta hermenéutica por un motivo temático y estructurante, "el reino del espíritu”, cuya reivindicación tiene, a mi juicio, una importancia crucial en nuestros días. En un

Universidad Complutense de Madrid

javierfabo@gmail.com 
horizonte intelectual en el que la palabra "espíritu" no pasa de ser más que una «abstracción exangüe», la elección de este motivo aparece como una invitación a reflexionar sobre el sentido y la legitimidad del mundo moderno, sobre su conexión con la metafísica y sobre la manera en que ésta culmina precisamente en la filosofía de Hegel. Todo ello en una época de la filosofía que se autocomprende como "postmoderna" y "postmetafísica", y para la que la renuncia a conceptos como "Espíritu" o "Absoluto" es la condición misma del sentido y la vigencia de Hegel en la actualidad. En este contexto, el trabajo de P. Cerezo aparece como un intento de recuperar el valor hermenéutico del concepto hegeliano de "espíritu", no sólo para comprender mejor a Hegel, sino también nuestra propia realidad cultural, pretendidamente postmoderna y secular, y que nada parece tener que ver ya con ese concepto.

Como no podía ser de otra manera, ello pasa necesariamente por analizar cómo esa realidad cultural ha leído a Hegel, y por hacerlo precisamente para clarificar algunas cuestiones pendientes del hegelianismo, como son el problema de las relaciones de Hegel con Spinoza (a propósito de la manifestación del Absoluto y de la exposición absoluta del Sistema), con Kant (a propósito de las relaciones entre derecho, moralidad y eticidad), con Marx (a propósito de las categorías de Entfremdung y Entäusserung) y con el cristianismo (a propósito de las relaciones entre sociedad y comunidad, Estado e Iglesia o filosofía y religión). En lo concerniente a estos temas, Hegel y el reino del espíritu es una valiosa contribución a los estudios sobre Hegel en lengua castellana ${ }^{2}$.

Junto a ésta, la otra gran aportación de este libro estriba en la crítica de algunos malentendidos y tergiversaciones ampliamente difundidos en torno a Hegel, de entre los que cabe destacar la interpretación del idealismo como forma de pensamiento puramente abstracta y subjetiva, que se limita a sobrevolar el mundo sin atenerse a la realidad particular, o la interpretación de lo especulativo como contemplación pasiva de la realidad, que se limita a reflejar (y, de esta manera, legitimar reaccionariamente) el statu quo como si de un espejo se tratara (Feuerbach), cuando no a compensar ideológicamente su finitud y su falta de realidad sustancial (Marx). Frente a estos tópicos, P. Cerezo reivindica la profundidad del principio idealista según el cual «todo lo racional es real y todo lo real es racional», incidiendo en su doble implicación: la naturaleza racional de la realidad efectiva (que alcanza su madurez como espíritu al término de su dialéctica real y de su historia) y la naturaleza activa del pensar (como actividad esencialmente práctica y transformadora del mundo).

Se cuestiona así otro de los lugares comunes generalmente asociados al idealismo: el de la insuperable dualidad de teoría y praxis, que articula también el contenido del libro que es objeto de consideración en dos partes bien diferenciadas: "horizontes teóricos" y "trayectos práxicos". Pareciera como si con ello el autor quisiera hacernos caer en el tipo de dualidades que el espíritu consiste en superar. Pronto se adivina, sin embargo, que si nos sumerge en esas dualidades no es para atraparnos y

2 Se comprende que, dada la naturaleza de esta recopilación, el autor haya renunciado a introducir modificaciones en el abundante cuerpo de citas de Hegel, y mantenga por eso la referencia a las traducciones usadas en el momento en que cada uno de estos trabajos fue redactado. Pero precisamente por las virtudes de todos ellos, y por la importancia objetiva de este volumen para los estudios sobre Hegel en lengua española, es de lamentar que no se haga mención en él, al menos en la bibliografía, de las nuevas y excelentes traducciones de Félix Duque (Ciencia de la Lógica), Manuel Jiménez Redondo y Antonio Gómez Ramos (Fenomenología del Espíritu), o de la edición Ricardo Ferrara de la Filosofía de la religión. 
retenernos en ellas, sino para que experimentemos desde dentro el proceso dialéctico que conduce inmanentemente más allá de las mismas, y para que asistamos (de la única manera en que ello resulta posible para un entendimiento finito, para el que la caída es insoslayable) al eclosionar de la infinitud del espíritu en el interior mismo de la finitud. Así es como el libro de P. Cerezo hace honor a la definición hegeliana del Absoluto como "unidad de lo finito y lo infinito", precisamente sin limitarse a repetir esta fórmula abstracta que, reiterada hasta la saciedad por el hegelianismo mediocre, ha acabado convirtiéndose en un mero eslogan que contribuye a alimentar el prejuicio generalizado sobre el carácter abstracto del pensamiento de Hegel.

En este prejuicio se cumplen los peores presentimientos de Hegel, siempre reacio a consignar su filosofía en este tipo de fórmulas que, a la manera de monedas acuñadas, pierden su escaso valor al ir circulando de mano en mano, separadas del marco textual al que pertenecen. Frente a estas consignas (que únicamente valen para sofocar momentáneamente la ansiedad del lector impaciente), Hegel reivindica la "paciencia del concepto", de un Absoluto que no se regala en pistoletazos de salida, sino sólo al final y como resultado del despliegue de la cosa misma. He aquí un precepto que la metodología de P. Cerezo sigue a rajatabla, volcada como está en mostrar el despliegue inmanente del espíritu en la filosofía de Hegel, lo cual sólo puede lograrse (y ello es clave) movilizando su extraordinaria riqueza de contenido. Movilizar esta extraordinaria riqueza es lo que casi dos siglos de hegelianismo exigen hacer hoy con el legado de Hegel, pero quizá también lo que hoy resulta tanto más difícil, cuando montañas de doxografía sepultan el tesoro original, y mediando irremediablemente nuestro acceso a él. En este contexto, el libro de P. Cerezo emerge como una esperanzadora respuesta a este requerimiento actual del hegelianismo. $\mathrm{Su}$ escritura consigue orientarse con destreza en las referencias doxográficas pertinentes, sin dejar de profundizar por ello en la verdadera sustancia del pensamiento hegeliano, en la riqueza del contenido, que procede (bien demuestra saberlo el autor) del reino de la finitud.

Dejar hablar a la cosa misma significa, en efecto, dejar hablar a la finitud, perseguir su despliegue a cada paso, a lo largo de sus innumerables trasformaciones dialécticas, atendiendo a la superación inmanente que se opera en ellas, pero no para aterrizar en el abismo y la vacía abstracción de la pura nada, sino para experimentar el poder de la negación, que es fundamentalmente, para Hegel, negación determinada, la negación de lo finito, vale decir, in-finitud. El de Hegel no es un pensamiento de la abstracción, sino de la infinitud. El que ambas designaciones puedan sonar a lo mismo para muchos se debe únicamente a su incapacidad para entender el significado que la palabra cobra en el idealismo especulativo de Hegel. El resultado de estas lecturas es un concepto del Absoluto que se aproxima más a la sustancia de Spinoza que al espíritu de Hegel. No debe extrañar, por tanto, que la clarificación de los malentendidos reduccionistas sobre este concepto acaben desembocando (como de hecho así ocurre en el libro de P. Cerezo) en una confrontación con el presunto "spinozismo hegeliano", del que tanto se habla en algunos círculos afines a Hegel, pero que reposaría en una mala intelección del concepto hegeliano de espíritu.

Al respecto, basta considerar la conocida formulación fenomenológica que exhorta a pensar el Absoluto «no sólo como sustancia, sino también y en la misma medida como sujeto», con la que Hegel se desmarca del spinozismo de la sustancia, y que desautoriza aquella «hermenéutica de las afinidades que lleva a difuminar los perfiles» (p. 105) entre pensamientos diferentes e inconmensurables. En su lugar, 
P. Cerezo apuesta por una «hermenéutica de las diferencias» (id.), que reconozca también las limitaciones del Sistema hegeliano para superar dialécticamente y asimilar la filosofía de Spinoza sin violentarla. Al integrarlo en su Sistema, Hegel habría ejercido una violencia sobre dicho pensamiento, «sacándolo de su verdadero quicio en una filosofía analítica de la expresión, para transportarlo a otro sintético conceptual de la exposición» (p. 135). Más que superado y asimilado, Spinoza aparece atravesado en el Sistema hegeliano, generando tensiones internas que conviene explicitar.

Algo semejante ocurre con la exégesis hegeliana de Kant, cuyo concepto de moralidad es asimilado en el Sistema como un momento del Espíritu objetivo, donde aparece como superación del derecho abstracto puramente exterior, pero también como momento asumido en la eticidad. Según P. Cerezo, ello implica la disolución de la individualidad y la autonomía, propias de aquella esfera, en la normatividad universal del Estado. El resultado es un Estado en el que no parece haber lugar para la libertad de conciencia y que «impide reconocer el pleno derecho formal a la autonomía moral» (p. 243), lo que a la luz de la experiencia histórica del último siglo hace plausible la identificación de la construcción hegeliana con la forma política del totalitarismo. Esta línea de consecuencias lleva al autor a preguntar si no debería haber en la eticidad un límite moral intrínseco capaz de prevenir esta deriva totalitaria, si el momento de la moralidad no está de hecho interiorizado en la eticidad, generando una «profunda tensión entre moralidad y eticidad en el pensamiento hegeliano» ( $p$. 248), tensión en la que «ambas dimensiones se implican pero a la vez se replican; se presuponen y hasta cierto punto se oponen; en una palabra, se envuelven y se limitan recíprocamente» (p. 250).

Aunque más adelante expresaré cierta reserva con respecto a esta interpretación del Estado hegeliano, no quería dejar de subrayar su presencia en este libro, precisamente como muestra de la distancia que P. Cerezo adopta frente a toda pretensión apologética: para él se trata, ciertamente, de reivindicar la figura de Hegel frente a las críticas reduccionistas y simplificadoras, pero sin caer en el fundamentalismo hegeliano que lo conduce todo al vórtice de su dialéctica, y para el que el Sistema aparecería como un gigantesco metabolismo capaz de asimilarlo todo, tanto las influencias pasadas, como las repercusiones futuras, en una totalidad que congregaría y condensaría toda la sustancia histórica del pasado, cancelando a la vez la posibilidad de todo acontecimiento futuro. Frente a este tipo de lecturas, P. Cerezo apuesta por una hermenéutica ecuánime, que reconoce tanto el valor como las limitaciones del Sistema hegeliano. Tales limitaciones tendrían que ver sobre todo, sostiene, con el carácter rígido y en ocasiones forzado del Sistema, pero también con el optimismo histórico-político, que habría llevado a Hegel a reconocer en el Estado burgués de su tiempo la esperada reconciliación del Espíritu: el «Reino de Dios en la tierra» o «Reino del espíritu».

Una reconciliación como ésta es algo que en todo caso la experiencia histórica del último siglo parece cuestionar, predisponiéndonos contra la identificación de pensamiento y realidad que cierra el Sistema hegeliano. La filosofía que se pensaba a sí misma como la expresión del «propio tiempo aprehendido en conceptos», pierde así su vigencia, lo que nos sitúa ante el problema de tener que reinterpretar y reapropiarnos su contenido, buscando nuevas maneras de reivindicar su actualidad. A la lectura de P. Cerezo es preciso reconocerle el valor de haber querido y sabido recoger el guante de este desafío hermenéutico, evitando caer en la tendencia 
dominante en el hegelianismo postmetafísico, que no ha podido reivindicar a Hegel sin renunciar al momento especulativo de la dialéctica, sacrificando inevitablemente a la crítica aquellos conceptos del Sistema que funcionan como operadores de su cierre (los conceptos de "Absoluto", "Espíritu", "Idea", etc.). El inevitable resultado es un hegelianismo que enmienda a Hegel, que pretende conducir a Hegel más allá de sí mismo (cuando no volverlo contra sí mismo), buscando en él tensiones internas que valdrían como la superación inmanente (y, por tanto, paradójicamente hegeliana) de su clausura sistemática; en definitiva: un "Hegel sin Sistema de Hegel" o, como muy acertadamente dice M. Jiménez Redondo ironizando sobre la "lectura débil" de Hegel, un «Hegel sin metafísica de Hegel» ${ }^{3}$, que «huye de la metafísica como de la peste» ${ }^{4}$, y que se parece cada vez más a ese «templo ricamente adornado, pero sin sagrario» ${ }^{5}$ con el que Hegel comparaba la pobreza espiritual de la cultura académica de su época.

Frente a estos excesos postmetafísicos, la lectura de P. Cerezo muestra cómo muchas de las críticas que se dirigen contra Hegel proceden de insuficiencias lectoras, cuya réplica pasa muchas veces por devolver la palabra a Hegel, por dejar que la corriente viva de su dialéctica acabe engulléndolas y superándolas. Ejemplo paradigmático de ello son las críticas de Feuerbach y Marx a la teoría hegeliana de la alienación (Entfremdung), que se desvanecen ante una lectura capaz de discernir adecuadamente este concepto de lo que Hegel llama "extrañamiento" (Entäusserung), así como de entender la inserción de ambos conceptos en la arquitectura fenomenológica. Ello pasa por aceptar que ambos momentos forman una unidad indisociable, que «no se supera mediante la crítica ilustrada de la conciencia religiosa [encerrada en sí mismo], como creía ingenuamente Feuerbach» (p. 102), ni tampoco mediante la superación de la alienación entendida a la manera marxista como «estado social de penuria» (p. 97). Ambos aspectos se atienen únicamente al lado negativo de la alienación, sin tener en cuenta el lado positivo de la misma: la «interpretación dinámica y productiva de la alienación» $(i d$.$) , expresada en la$ palabra "extrañamiento". Conforme a esta interpretación, el espíritu «se exterioriza, renunciando a sí, [...] produciendo con ello un mundo, que no puede reconocer de inmediato como suyo, pero donde lleva a cabo la plasmación de su poder» (p. 97), y que «no puede menos de producir objetividad» (p. 98), con la consiguiente «renuncia a la libertad abstracta y formal» $(i d$.). Se colige de ahí que la alienación no es un estado pasajero que pudiera quedar superado (como pretenden Marx y Feuerbach), sino (como dice Hyppolite) «un problema universal, el de la conciencia humana de sí misma, que incapaz de pensarse como un cogito separado, no se encuentra más que en el mundo que edifica, y que sólo puede alcanzar su autotransparencia en el lenguaje del reconocimiento» (p. 103).

Las páginas de P. Cerezo sobre la alienación son una clara muestra de que reivindicar la actualidad de Hegel pasa necesariamente por recuperar aquellos conceptos que Hegel sitúa en el centro de su Sistema, pero que no han podido abrirse camino en un Occidente crecientemente secularizado. En este contexto, debe elogiarse la valentía que supone colocar el concepto cristiano de "espíritu" en el

Jiménez Redondo, M.: "Palabra, tiempo y concepto en el pensamiento de Hegel", Suplemento de Contrastes: Revista internacional de filosofia, 15, 2, p. 152.

4 Hegel, G. W. F.: Jenaer Schriften, Frankfurt, Suhrkamp, 1970, p. 575.

5 Hegel, G. W. F.: Ciencia de la lógica (I), Madrid, Abada, 2011, p. 183. 
centro de una lectura que pretende reivindicar la actualidad de la figura de Hegel, reconociendo precisamente en este concepto la fuente inagotable de su vigencia y su vitalidad. Como no podía ser de otra manera, ello pasa por posicionarse frente a interpretaciones como la de Feuerbach, que no ven en el Espíritu hegeliano más que una mistificación teológica, y cuya pretensión no es otra que la de subvertir la relación que naturaleza y espíritu mantienen en la sistemática hegeliana: si para Hegel la naturaleza es la enajenación del espíritu, para Feuerbach el espíritu es la enajenación de la naturaleza. El resultado es una devaluación del espíritu, de la que el autor no duda en hacer corresponsable a la propia retórica idealista: «La palabra "espíritu" nos resulta devaluada tanto por su abuso retórico en el contexto idealista, como por la actitud desdeñosa de casi dos siglos de materialismo, positivismo y utilitarismo, fundidos con frecuencia en una política práctica de la eficiencia» ( $\mathrm{p}$. 10). En este contexto, el libro de P. Cerezo se presenta como un decidido intento de recuperar y revalorizar este concepto absolutamente central del Sistema hegeliano, no sólo para reconstruir su significado teórico e histórico preciso, sino para reivindicar su actualidad: «[...] el espíritu no es una abstracción exangüe, como ha pretendido hacernos creer la filosofía materialista de inspiración feuerbachiana marxista cuya crítica, dicho sea de paso, paradójicamente ya está anticipada en Hegel, ni tampoco el ensueño de un humanismo ebrio de subjetividad, al modo romántico, que también fue objeto del acerado criticismo hegeliano» (id.).

Apenas resulta posible reprimir la perplejidad que despierta el hecho de que el concepto de espíritu vuelva a suscitar interés en una época como la nuestra, que se autoconcibe como heredera del desierto anunciado por Nietzsche. ¿Subyace a este renovado interés un prurito puramente erudito, una deferencia puramente conmemorativa, o cabe entrever en él una reacción ante el avance ese desierto y la necesaria erosión que produce en un Sistema como el de Hegel? ¿Estamos acaso ante el desenlace de aquella época que creía haber llegado al final de sus días, o más bien ante el comienzo de una mejor comprensión de lo que significa (¿ha significado?) ese "final”? ¿Qué significa, en definitiva, la reaparición de esta categoría crepuscular y emblemática de final de la modernidad más allá de ese final? ¿Sobrevive acaso el espíritu a su ocaso y a su propio final? ¿O el renovado interés que suscita hoy en día es la prueba palpable de que ese final nunca aconteció, de que nunca aconteció al menos en el sentido postmetafísico de la liquidación del orden precedente, sino en el de la consumación y la maduración espiritual del mismo, de la que todavía seguimos formando parte en cierta manera?

He aquí algunas preguntas que la reaparición del espíritu en la escena postmetafísica debe encarar con franqueza y claridad, pero que el libro de P. cerezo no llega a abordar directamente, incurriendo así en cierta indefinición. La hermenéutica ecuánime que tan acertada resulta en algunos puntos, adolece en éste de cierta ambigüedad: si, de un lado, se trata de recuperar los conceptos que tanto hegelianos como antihegelianos se han apresurado a rechazar como partes malditas del Sistema, de otro se trata más bien de «reactualizar su potencial de sentido», llegando incluso a renunciar a algunos de ellos (como en el caso del concepto hegeliano del Estado). Se pretende evitar así caer en la nostalgia restauradora, salvando «lo que perdura del espíritu hegeliano, aun cuando ya sin el aura de su consagración metafísica» (p. 12), lo que necesariamente exige reivindicar la faceta histórico-real (y no meramente lógicometafísica) del espíritu como "libertad"; como libertad, ciertamente, subjetiva (pues «"espíritu” significa también interioridad o ser para sí en la máxima experiencia 
de la negatividad», p. 11), pero también objetiva, toda vez que la del espíritu es una interioridad concreta y real: «El espíritu sabe de sí en su propia manifestación, al objetivarse y hacerse mundo» (id.), y ello tanto en el sentido natural (donde la libertad se expresa como técnica), como propiamente espiritual (donde tiene lugar el encuentro de las diferentes libertades). De ahí que P. Cerezo afirme finalmente que, «en un tercer sentido, "espíritu” es también comunidad racional, [...] obra en común de la intersubjetividad, que dialoga, trabaja y actúa. Comunidad y personalidad se conjugan, pues, en la vida del espíritu» (id.).

He aquí las coordenadas hermenéuticas, genuinamente hegelianas, desde las que P. Cerezo reivindica la actualidad del espíritu. Las mismas desde las que rechaza, sin embargo, la sacralización del Estado que cerraría el Sistema hegeliano, y en la que cree reconocer la sombra de un totalitarismo larvado, que corre «el riesgo más grave de degenerar en alguna forma de integrismo cultural/religioso» (p. 374), convirtiéndose con ello en «un impedimento para la praxis política de convivencia» (id.). En este punto, la lectura de P. Cerezo parece desembocar en un tópico del hegelianismo: un tópico que no sólo la aproxima entonces a ese hegelianismo postmetafísico incapaz de reivindicar la actualidad de Hegel sin renunciar a los aspectos más sistemáticos de su filosofía, sino que debilita el motivo central de su propia propuesta exegética, basada en la reivindicación de la faceta histórico-real del espíritu como libertad. Pues, ¿qué otra cosa significa esta libertad sino la capacidad de realizar la acción humana en el mundo? ¿Qué otra cosa es el Estado hegeliano sino la objetivación de esta libertad? Cuanto más insiste el autor en reivindicar la dimensión del espíritu como libertad menos se entiende su renuncia al que sería el epítome de su expresión real en el Sistema. Menos se entiende incluso la elección de la expresión hegeliana que da título a la obra. Pues, ¿qué otra cosa significa para Hegel "reino del espíritu" sino justamente "Estado"? Todo ocurre como si el mismo motivo central y estructurador que permite al autor ir disolviendo con eficacia los tópicos y malentendidos en torno a Hegel a lo largo de la obra, apareciera en las últimas páginas envuelto él mismo en un tópico, y denunciado entonces como un grave error de Hegel.

La acusación de totalitarismo parece propia, en efecto, de quienes se apresuran a criticar la doctrina hegeliana del Estado sin haber profundizado adecuadamente en los momentos de la eticidad y de la religión, que anteceden a su doble aparición en el Espíritu objetivo y absoluto respectivamente. Esos lectores incurren con ello en una crítica muy parecida a la que el propio Hegel dirige contra el derecho (cuyo carácter abstracto hace que deba imponerse externa y coactivamente) y contra la moralidad (cuyo carácter subjetivo la sume en una singularidad que no puede evitar aparecer a ojos de las demás conciencias como fanatismo). Una insuficiencia lectora como ésta es, sin embargo, algo que en modo alguno puede imputarse a P. Cerezo, que dedica bastantes páginas al análisis del "Espíritu objetivo". Más bien parece como si en sus conclusiones no acabara de extraer las implicaciones de su propio análisis, como si algo interfiriera en el momento decisivo e impidiera reconocer en el Estado la expresión más viva y real del espíritu hegeliano. ¿Es nuestra experiencia histórica del totalitarismo europeo lo que impide seguir a Hegel en este punto? ¿Es nuestra sensibilidad democrática lo que se solivianta ante la necesaria coincidencia de moralidad y derecho en el Estado hegeliano, impidiéndonos reconocer en ella la mejor garantía contra el totalitarismo?

El hecho de que los regímenes totalitarios sólo puedan forjar esa coincidencia por la fuerza (silenciando, reprimiendo e incluso matando a sus Sócrates) es el síntoma 
más inequívoco de que carecen de ella; de que carecen de ella al menos al nivel concreto y real del contenido sustancial, y de que sólo pueden emularla en un sentido puramente extrínseco y artificial. Es este cierre artificial (y no el cierre mismo como tal) lo que debe juzgarse como totalitario. Imputar este cargo al Estado hegeliano es ignorar la inmanencia de su cierre, en el que la reconciliación de derecho y moralidad procede de la necesidad de la cosa misma. Es la superación misma del carácter puramente abstracto del derecho lo que lo reconcilia con la singularidad de la moralidad; recíprocamente, es la superación misma del carácter puramente subjetivo de la moralidad lo que la reconcilia con la universalidad del derecho. En un Estado que se basa en esta reconciliación recíproca, ni el derecho tiene la necesidad de hacerse valer externamente (pues, al coincidir con el contenido de la conciencia moral, brota espontáneamente en sus máximas), ni la moral tiene por qué hacerse valer fanáticamente (pues al coincidir con el contenido del derecho puede ser reconocida por el Estado, que le otorga así su garantía).

La identidad sustancial de derecho y moralidad interviene así como la mejor garantía contra el totalitarismo, pues tal identidad es la garantía de que ni la moralidad (si verdaderamente funda su certeza en la libertad del espíritu) puede infundir en el ciudadano nada que contraríe el derecho del Estado, ni tampoco el derecho (si verdaderamente funda su universalidad en el contenido del espíritu) puede cohibir la libertad de la conciencia individual; bien entendido que si la conciencia moral no puede discrepar con el Estado hegeliano no es porque éste se lo prohíba, sino porque no tiene la necesidad de hacerlo. La verdadera moralidad no encuentra motivos para discrepar en un verdadero Estado, cuya misión no es otra que la de hacer valer en el mundo el mismo contenido sustancial que ella descubre en lo más profundo de su autoconciencia. Por la misma razón, tampoco la verdadera religión encuentra motivos para disputar al Estado el gobierno del mundo, pues el Estado se encarga de reformarlo según los requerimientos del mismo espíritu que ella proclama. La labor de la verdadera Iglesia no es gobernar el mundo, sino educar los espíritus de quienes deben habitarlo, para que descubran en su subjetividad interior la universalidad del derecho. Sin esta colaboración, el Estado sólo podría instruir súbditos obedientes, mas no ciudadanos libres capaces (como Sócrates) de amar las buenas leyes y sentirlas como propias. Y es que sólo un espíritu religioso que se ha reconciliado con su esencia espiritual puede dejar de relacionarse con la ley del Estado como algo meramente positivo y dejar de sentir su poder como algo coactivo, descubriendo en la universalidad de su derecho la expresión objetiva de su propio espíritu individual, y encontrando en la obediencia al Estado su más plena libertad.

Se colige de ahí que sólo un Estado que cuente con la Iglesia para esta tarea pedagógica puede alejar de sí toda sombra de totalitarismo; incluida aquella forma de "totalitarismo" que algunos creen adivinar tras las actuaciones policiales y los tribunales de justicia. Pero si esto es así, ni cabe imputar a Hegel una "sacralización del Estado" (sino más bien una suerte de "estatalización de la religión", que le reconocería cierto derecho de ciudadanía como educadora del espíritu), ni tampoco una "religión de Estado" al estilo de los regímenes fanáticos. Hegel es perfectamente consciente de que ni «el cristianismo puede ser o funcionar como una religión política o del Estado sin traicionar su requerimiento al Reino de Dios, ni el Estado puede enfeudarse con el cristianismo sin perder su autonomía ante la presión de los derechos sagrados de conciencia, que pretenden ser superiores» (p. 323). Un dilema como éste atraviesa de lado a lado el pensamiento de Hegel y es perseguido por P. 
Cerezo con auténtico rigor y precisión en las diferentes etapas de su evolución, desde sus inicios en el joven Hegel (al calor de sus lecturas de Kant y Rousseau) hasta la etapa de Berlín. Su resolución en el Sistema de madurez se resume en la tesis hegeliana de la armonía de Iglesia y Estado, basada en el mutuo reconocimiento de ambas esferas, que no es sino el reconocimiento de que tanto la doctrina de la Iglesia como el derecho del Estado se fundan en la unidad del espíritu absoluto.

Atendiendo a esta unidad, P. Cerezo reconoce que «conforme a la lógica interna del sistema hegeliano, cabría pensar que el caso Sócrates no es posible hoy, pues nuestro mundo ético ha integrado ya la mejor herencia socrática de la libertad de conciencia» (p. 241). Una libertad como ésta era algo que en modo alguno podía admitir la eticidad inmediata del mundo griego, en la que el derecho del Estado se identificaba con las costumbres contingentes de la ciudad, pero sí la eticidad desarrollada del Estado hegeliano, donde el derecho ha superado la abstracción que lo enfrentaba a la moralidad (obligándola a retraerse al fuero interno de su subjetividad), y donde el contenido de esa moralidad ha llegado a coincidir con el del derecho universal. En una eticidad como ésta, no puede tener lugar ya la «tragedia en lo ético» (pp. 235 y ss.) que implica la muerte de Sócrates, y que Hegel considera como «la tragedia [misma] de Grecia» ${ }^{6}$ : ésta, escribe Hegel, «no es, por tanto, solamente la destrucción de un individuo, sino que todos se hallan implicados en ella; era, en realidad, un crimen que el espíritu del pueblo perpetraba contra sí mismo. [...]. Es la disolución de este pueblo, cuyo espíritu, por tanto, pronto veremos desaparecer del mundo. Pero de tal modo, que de sus cenizas surgirá otro más alto, pues el Espíritu del Mundo se eleva ahora al plano de una conciencia superior» ${ }^{7}$. Ese plano es la conciencia del mundo moderno, que el cristianismo reconciliará con el principio de la moralidad anticipado por Sócrates, y en el que éste encontraría (como ocurre con los héroes en la Historia) su redención:

Tal es siempre la posición y el destino de los héroes en la historia universal que hacen nacer un mundo nuevo cuyo principio se halla en contradicción con el mundo anterior y lo desintegra: los héroes aparecen, pues, como la violencia que infringe la ley. Perecen en lo individual; pero perece solamente el individuo, no el principio en él encarnado, que la pena impuesta a aquel no alcanza a destruir. En el caso concreto de Sócrates, el espíritu del pueblo ateniense no se restaura en su plenitud por el hecho de que Sócrates desaparezca. Se elimina la forma falsa de la individualidad, y además violentamente, mediante un castigo; pero el principio mismo se abre paso, si bien de otra forma, y se eleva a principio del Espíritu del Mundo. ${ }^{8}$

No quería concluir esta reseña sin comentar esta necesaria consecuencia del Sistema hegeliano, que P. Cerezo parece ver con escepticismo. No es que en el Estado hegeliano no pueda haber un Sócrates, sino que no puede no haberlo. Lo que en ningún caso puede haber en él es, sin embargo, el "caso Sócrates", toda vez que Sócrates no tendría en él la necesidad de "hacer de Sócrates", de ser "el tábano de Atenas": su papel como crítico de la sociedad cedería necesariamente ante el de educador del espíritu, indudablemente más afín a su vocación pedagógica (y quizá

\footnotetext{
Hegel, G. W. F.: Lecciones de historia de la filosofia (II), México, F.C.E., 2002, p. 98.

Ibid., pp. 98-99.

Ibid., p. 96.
} 
también religiosa). Pero si esto es así, el Estado hegeliano no puede identificarse con ninguno de los que han existido en la Historia, ni siquiera con el Estado prusiano de su época. Esta precipitada identificación es quizá lo que produce la apariencia de pensamiento reaccionario y totalitario. Apariencia que se desvanece, sin embargo, cuando recordamos que el Estado con el que culmina el Sistema hegeliano no acontece en la esfera de la Historia (que cierra el Espíritu objetivo), sino en la del Espíritu absoluto, precisamente como la condición última de inteligibilidad de los Estados históricos, y justamente en esa medida, como la instancia inmanente de su crítica. En el ámbito de la Historia universal, el Estado hegeliano ha empezado, pero permanece esencialmente venidero. 